\title{
TWO-MINUTE PERIPHERAL MOTION CONTRAST THRESHOLD TEST PREDICTS OLDER DRIVERS' COLLISIONS AND HAZARDOUS DRIVING IN SIMULATOR
}

\author{
Steven Henderson, Charles Collin ${ }^{1}$, Sylvain Gagnon ${ }^{1}$, Misha Voloaca ${ }^{1}$, Heather \\ Woods-Fry ${ }^{1}$, John Grant ${ }^{2}$, Ted Rosenthal ${ }^{2}$ \& Wade Allen ${ }^{2}$ \\ ${ }^{1}$ Department of Psychology, University of Ottawa, Ottawa, Ontario, Canada \\ ${ }^{2}$ Systems Technology Incorporated, Hawthorne, California, USA \\ Email: steven.henderson@rogers.com
}

\begin{abstract}
Summary: Older drivers’ contrast thresholds for low spatial frequency drifting Gabor stimuli at 15 degrees eccentricity were measured with a previously validated 10-minute forced-choice test and a 2-minute increasing contrast detection test (implemented on an iMac and a PC). Older drivers' contrast thresholds significantly predict collisions, near collisions, hazardous lane excursions, and speeding, during a simulated drive with surprising hazard encounters and highway merging tasks. The 2-minute tests also correlate with each other and with the 10-minute test. The 2-minute tests are potentially suitable for use in an operational driver assessment setting.
\end{abstract}

\section{INTRODUCTION}

Older drivers have more crashes per mile beginning at about the age of 70, and the trend accelerates markedly by the age of 80 (Eberhard, 2008; Li, Braver, and Chen, 2003; NHTSA, 2001). Compounding this age-related accident risk, the population over 65 will more than double over the next 30 years (U.S. Census Bureau, 2008), and an increasing proportion of that population will be active drivers (Cheung and McCartt, 2011). Although frailty accounts for some of the age-related fatality increase, insurance-only crashes also show the same rising curve with age, albeit less extreme (Highway Loss Data Institute, 2010). Older drivers are overrepresented in multiple vehicle crashes at intersections (Bao and Boyle, 2009; Clarke, Ward, Truman, and Bartle, 2009; Stamatiadis and Deacon, 1995), most often after they have committed the right-of-way (ROW) violation that caused the crash (Clarke, Ward, Bartle and Truman, 2010; Di Stefano and Macdonald, 2003; Langford and Koppel, 2006; Massie, Campbell, and Williams, 1995; Mayhew, Simpson, and Ferguson, 2006). Errors of attention (i.e., visual detection failures) are the primary age-related causal factor of intersection crashes (Oxley, Fildes, Corben, and Langford, 2006; Summala and Mikkola, 1994).

It follows that an age-related visual deficit may be an underlying causal factor for some of the increase in accident rate with age. Specifically, numerous researchers have shown that visual motion processing relates to accident risk and/or driving performance (Conlon and Herkes, 2008; De Raedt and Ponjaert-Kristoffersen, 2000; Raghuram and Lakshminarayanan, 2006; Wood et al., 2008). As well, numerous visual perception investigators have demonstrated age-related deficits in contrast sensitivity for stationary low spatial frequency sine wave gratings in peripheral vision (Schefrin, Tregear, Harvey and Werner, 1999), drifting or counter-phase flickering low spatial frequency gratings in central vision (Owsley, Sekuler and Siemsen, 1983; Sekuler and Hutman, 1980; Sekular, Hutman and Owsley, 1980), and coherence thresholds for random dot stimuli drifting in peripheral and central vision at a retinal velocity similar to that of the driving environment (Atchley and Anderson, 1998). 
The age-related contrast sensitivity decline at low spatial frequencies and high temporal frequencies is likely due to magnocellular channels’ decline with age (Conlon and Herkes, 2008). The magnocellular channels are responsible for detecting movement, identifying its retinal location, and allocating attention to that location (Chikashi et al., 1999; Horwitz and Newsome, 1999; Livingstone and Hubel, 1988; Steinman, Steinman and Lehmkuhle,1997). Age-related magnocellular channel deficiencies would be expected to impair orienting on motion, which is precisely the visual function that drivers use to detect and respond to approaching vehicles.

Because the magnocellular channel is optimally responsive to low spatial frequencies (below about 1.5 cpd; Skottun, 2000), is responsive to relatively higher temporal frequencies than the sustained, form-processing parvocellular pathway (Skottun and Skoyles, 2008), and is relatively more peripherally distributed than the parvocellular pathway, an optimal magnocellular channel stimulus is a low spatial frequency, high temporal frequency sine wave grating in the near visual periphery. We hypothesize that an age-related deficit in orienting on and detecting approaching vehicles will be captured by measuring peripheral motion contrast threshold (PMCT) for this optimal stimulus. Our group has previously shown that older drivers' PMCT for such a stimulus significantly predicts their self-reported accident risk (Henderson and Donderi, 2005; Henderson, Gagnon, Bélanger, Tabone, and Collin, 2010) and their simulator performance (Henderson, Gagnon, Collin, Tabone, and Stinchcombe, 2013).

However, our previous PMCT test requires approximately 10 minutes to complete, making it too long to include in an operational driver assessment battery, which should require only 15 minutes in total to complete (Staplin, Lococo, Gish, and Decina, 2003). The current study is intended to validate a new 2-minute PMCT test (a two-alternative increasing contrast to detection procedure) against the 10-minute forced-choice PMCT test, and against driving simulator performance. In addition to testing to determine if PMCT was directly associated with collision risk and inversely associated with hazard perception (nearness of approach to hazards), we tested the hypothesis that PMCT would be associated with poor lane-keeping (i.e., directly associated with hazardous lane deviation time), because heading control depends on visual information processing of peripheral flow.

\section{METHOD}

\section{Participants}

Younger participants $(\mathrm{N}=25,19-58$ years, $M=25.4, S D=8.6)$ received course credits to participate in the study. Older drivers ( $\mathrm{N}=26,65-83$ years, $M=69.7, S D=4.7)$ were recruited through advertisements in the community and from a previous study on simulated driving and were compensated 20 dollars for their participation. Five older participants did not complete the experiment due to simulator sickness. However, previous studies have shown that dropouts due simulator sickness were not found to differ from completers on most measures (Mullen, Weaver, Riendeau, Morrison, and Bédard, 2010). Data were combed for outliers ( \pm 2.5 SD) in the various PMCT tests, and as a result one older participant and one younger participant were excluded from analysis of PMCT-10 data. All participants read a summary of the study and consented to participate before testing commenced. 


\section{Vision measures}

We tested older drivers on three versions of the PMCT test: A 10-minute version using the forced-choice Method of Descending Limits and two 2-minute versions using the Ascending Békésy Method (i.e., continuous rise in stimulus contrast until detection). The only difference between the two 2-minute versions was the platform on which they were implemented: One was programmed in Matlab, and presented on an iMac, the other was programmed in $\mathrm{C}++$ and presented on a PC. For all PMCT tests, all displays were gamma-corrected. Stimulus contrast was recorded in decibel units $(\mathrm{dB})$, which is $20 * \log$ (Michelson contrast), although data were converted to Michelson contrast $\left(\mathrm{L}_{\max }-\mathrm{L}_{\min }\right) /\left(\mathrm{L}_{\max }+\mathrm{L}_{\min }\right)$ for statistical analysis.

Two-minute PMCT tests. Using the Ascending Békésy Method, PMCT was determined for Gabor wavelet stimuli (i.e., a vertical sine wave luminance grating of .4 cycles $/{ }^{\circ}$ spatial frequency, scrolling centripetally at $13.75 \%$ sec within a Gaussian contrast envelope spanning $10^{\circ}$ ) presented at $15^{\circ}$ horizontal eccentricity, either directly left or right of fixation. After two highly visible practice stimuli were shown at $-10 \mathrm{~dB}, 10$ trials were run, with side order randomly shuffled. Gabor contrast began at $-50 \mathrm{~dB}$, and increased smoothly at $2 \mathrm{~dB} / \mathrm{second}$. The participant indicated the side of presentation as soon as possible. Trials were separated by a randomly-chosen interval of 2 , 3, or 4 seconds in order to mitigate anticipation effects.

The 2-minute PMCT tests were implemented on a PC (Quad Core i5 @ 2.9 Ghz, driving an ASUS 10-bit monitor) and on a Mac computer (28" iMac 3.2 Ghz i3 processor with OSX 10.6.8, using Matlab version 2010b, running PsychToolbox and custom software). The iMac was viewed from $57.3 \mathrm{~cm}$, and the PC from $72 \mathrm{~cm}$. The 2-minute versions were otherwise identical.

Ten minute PMCT test. This spatial 2-alternative forced choice method of descending limits procedure also used 0.4 cycles $/{ }^{\circ}$ Gabor stimuli, and has been described in detail in Henderson et al (2009, 2013).

Other measures. Snellen visual acuity, simple reaction time and choice reaction time were also measured.

\section{Simulator}

The STISIM Drive ${ }^{\circledR}$ version 3.0 was used to generate and present the simulated environment. Simulations were projected on three $138 \mathrm{~cm}$ X $91 \mathrm{~cm}$ white boards located approximately 160 $\mathrm{cm}$ in front of the seated participants, giving a viewing angle of 180 degrees. We used a modified Logitech G25 steering wheel and pedals from Extreme Competition Controls Inc (ECCI). The STISIM Drive software collects several variables at a rate of $10 \mathrm{~Hz}$.

\section{Procedure}

Simulator scenarios. Participants drove on the right side of the road, and were exposed to three scenarios; a familiarization scenario, a highway merging scenario and a city scenario containing a series of surprising events. In the familiarization scenario, participants drove on a $5.7 \mathrm{~km}$ two lane road and learned to maintain speed, stop, and turn left and right at intersections.

The highway merging scenario was $10.3 \mathrm{~km}$ long and required numerous entries onto a three lane highway. On the highway, participants had to move either to the left-most or the right-most lane. 
They were also told to change lanes several times after the second exit and this was forced by the presence of stopped cars on their lane. The amount of traffic increased over time, making it increasingly difficult for participants to perform a lane change.

The city scenario with surprising event was $7.8 \mathrm{~km}$ long. The drive started in a city downtown environment, went through a small town, followed by a rural road, and then back into a city. The posted speed limits ranged from 50 to $100 \mathrm{~km} / \mathrm{h}$. Participants were asked to do four turns (3 right, 1 left). There were 5 unexpected events, as follows: 1) on a 6-lane road, a car merged onto the road from a gas station on the right; 2) on a 6-lane road, a car ran a red light from the left just as the participant was crossing an intersection; 3) on a 2-lane road, a car merged onto the road from the shoulder; 4) on a 2-lane road at $5 \mathrm{~km}$, a moose ran across the road from the right; and 5) on a 4-lane road, a car merged unto the road from a right-side merging lane.

PMCT vision test order was counterbalanced across participants. Simulator scenarios were presented in the following order; familiarization, city scenario and highway merging. On average, testing lasted 60-75 minutes.

\section{RESULTS AND DISCUSSION}

Age-related differences in PMCT. (The Anderson-Darling Test for Normality supported the assumption of normality for all PMCT and simulator data.) The hypothesis that PMCT scores will predict hazardous driving in older individuals is based on the research showing that magnocellular function declines with age (Conlon and Herkes, 2008). To test for age-related declines in motion processing, we ran a between-groups t-test on PMCT scores from all three variants of the test. This showed highly significant differences between older and younger participants for all three variants: PMCT-10, $\mathrm{t}=-4.661, \mathrm{p}<.0001$, PMCT-2(PC), $\mathrm{t}=-4.877$, $\mathrm{p}<.0001$; PMCT-2(iMac): $\mathrm{t}=-4.998, \mathrm{p}<.0001$. In all cases, older participants had higher mean PMCT thresholds than younger ones.

Older participants also showed markedly greater ranges of PMCT scores. For instance, the range of scores for younger drivers on PMCT-2(iMac) was .76\% for young drivers, while that for older drivers was $2.23 \%$, almost three times as great. These results are consistent with the assumption that peripheral motion contrast threshold rises with age, and that it does so more in some individuals than others, thus producing a greater spread of scores in the older group.

Comparison of different PMCT versions. Results showed a very high correlation between the different versions of the test. For older participants, Pearson r correlation coefficients between contrast thresholds measured with PMCT-10 and those measured with PMCT-2 were .78 (PC; $p$ $<.00001$ ) and .84 (Mac; $p<.00001$ ). Despite differences in psychophysical method, the 2minute tests agreed well with the 10-minute test. The correlation between contrast thresholds measured with the two 2-minute versions was even higher, at .89 $(p<.000001)$. This result suggests the two implementations provide very similar results despite differences in hardware and software, and that PMCT measurements in general are highly repeatable in an older population. Similar correlations were calculated for younger participants. These were significant, but lower. For instance, the correlation between the two 2-minute implementations was .52 ( $p<$. 01 ). This is likely due to range restriction, as the younger participants showed a very small range of scores. These correlations suggest that in older individuals the PMCT-2 measurements are highly repeatable in an older population with no order or practice effects observed. 
Relationship between hazardous simulated driving and PMCT scores. Our primary goal was to assess PMCT's ability to predict hazardous driving behaviour in older subjects. Table 1 contains correlation coefficients and 1-tailed probabilities between contrast thresholds and simulator measures associated with unsafe driving.

Table 1. Correlations and probabilities between PMCT scores and hazardous driving measures

\begin{tabular}{|l|l|l|l|}
\hline & 2-min iMac & 2-min PC & 10-min PMCT \\
\hline Number of collisions & $+.66, p=.0008$ & $+.45, p=.024$ & $+.55, p=.006$ \\
\hline Min distance of approach to hazards & $-.47, p=.019$ & $-.39, p=.047$ & $-.55, p=.006$ \\
\hline Min distance of approach to lateral hazards & $-.61, p=.002$ & $-.48, p=.016$ & $-.64, p=.001$ \\
\hline Total hazardous lane deviation time & $+.41, p=.036$ & $+.24,(\mathrm{~ns})$ & $+.41, p=.036$ \\
\hline
\end{tabular}

All PMCT measures significantly predict collision risk with vehicles and other hazards, consistent with the hypothesis that PMCT captures an age-related deficit in orienting on and detecting approaching vehicles and other hazards. All PMCT measures significantly predict minimum distance of approach to hazards, consistent with the hypothesis that declining sensitivity of the magnocellular pathway (i.e., rising PMCT) is associated with late detection and reduced margin for errors). This result, in combination with the collision result, suggests that PMCT can help predict risk of collision or near-collision. There is also a significant positive correlation between some PMCT scores and total hazardous lane deviation time (i.e., crossing the centerline into oncoming traffic or making abortive attempts to change lanes in a highway scenario), likely related both to deficient processing of peripheral flow, and to late detection of adjacent vehicles.

\section{CONCLUSION}

The results show that as older drivers' PMCT scores rise, they become more prone to crash, and to make dangerous lane deviations in simulated driving scenarios. These results suggest this tool will be useful in predicting collision risk among older drivers. Furthermore, PMCT is easy to administer, easy to take, and requires only 2 minutes to implement, making it an excellent candidate for a field-deployable driving assessment tool.

\section{ACKNOWLEDGEMENTS}

This research was supported by a SBIR grant from the National Center for Injury Prevention and Control to Systems Technology, Inc. in collaboration with Dr. Sylvain Gagnon and Dr. Charles Collin of the Department of Psychology, University of Ottawa. Dr. Steven Henderson was financially compensated as a research consultant on the project.

\section{REFERENCES}

Atchley, P., \& Anderson, G. J. (1998). The effect of age, retinal eccentricity, and speed on detection of optic flow components. Psychology and Aging, 13, 297-308.

Bao, S., \& Boyle, L. N. (2009). Age-related differences in visual scanning at median-divided highway intersections in rural areas. Accident Analysis and Prevention, 41, 146-152.

Cheung, I., \& McCartt, A. T. ( 2011). Declines in fatal crashes of older drivers: Changes in crash risk and survivability. Accident Analysis and Prevention, 43, 666-674. 
Chikashi, M., Okubo, M., \& Mugishima, M. O. (1999). Effects of background color on the global and local processing of hierarchically organized stimuli. Journal of Cognitive Neuroscience, 11, 1-8.

Conlon, E. \& Herkes, K. (2008). Spatial and temporal processing in healthy aging: Implications for perceptions of driving skills. Aging, Neuropsychology, and Cognition, 15, 446-470.

Clarke, D. D., Ward, P., Bartle, C., \& Truman, W. (2010). Older drivers' road traffic crashes in the UK. Accident Analysis and Prevention, 42, 1018-1024.

Clarke, D. D., Ward, P., Truman, W. \& Bartle, C. (2009). Collisions Involving Older Drivers: An In-depth Study. Road Safety Research Report 109. London: Department for Transport.

De Raedt, R. \& Ponjaert-Kristoffersen, I. (2000). Can strategic and tactical compensation reduce crash risk in older drivers? Age and Ageing, 29, 517-521.

Di Stefano, M. D., \& MacDonald, W. (2003). Assessment of older drivers: Relationships among on-road errors, medical conditions, and test outcome. Journal of Safety Research, 34, 415429.

Eberhard, J. (2008). 'Older drivers' 'high per mile crash involvement'-the implications for licensing authorities. Traffic Injury Prevention, 9, 284-290.

Henderson, A. S. \& Donderi, D. C. (2005). Peripheral motion contrast sensitivity and older drivers' detection failure accident risk. Proceedings of the Third International Driving Symposium on Human Factors in Driver Assessment, Training and Vehicle Design, 41-50, Rockport, Maine, 2005.

Henderson, A. S, Gagnon, S., Bélanger, A., Tabone, R., \& Collin, C. (2010). Near peripheral motion detection threshold correlates with self-reported failures of attention in younger and older drivers. Accident Analysis \& Prevention, 42, 1189-1194.

Henderson, A. S, Gagnon, S., Collin, C., Tabone, R., \& Stinchcombe, A. (2009). Near peripheral motion detection threshold predicts older drivers' simulator performance. Proceedings of the Fifth International Driving Symposium on Human Factors in Driver Assessment, Training and Vehicle Design, 334-341, Big Sky, Montana, 2009.

Henderson, A. S, Gagnon, S., Collin, C., Tabone, R., \& Stinchcombe, A. (2013). Near peripheral motion detection threshold predicts older drivers' simulator performance. Accident Analysis \& Prevention, 50, 103-109.

Highway Loss Data Institute (2010). Q\&As: Older People. Retrieved from http://www.iihs.org/research/qanda/older_people.html\#2

Horwitz, G. D. \& Newsome, W. T. (1999). Separate signals for target selection and movement specification in the superior colliculus. Science, 284, 1158-1161.

Langford, J. \& Koppel, S. (2006). Epidemiology of older driver crashes - identifying older driver risk factors and exposure patterns. Transportation Research Part F, 9, 309-321.

Li, G., Braver, E., \& Chen, L. (2003). Fragility versus excessive crash involvement as determinants of high death rates per vehicle-mile of travel among older drivers. Accident Analyses and Prevention, 35, 227-235.

Livingstone, M., \& Hubel, D. (1988). Segregation of form, color, movement, and depth: Anatomy, physiology, and perception. Science, 240, 740-749.

Massie, D. L., Campbell, K. L., \& Williams, A. F. (1995). Traffic accident involvement rates by driver age and gender. Accident Analysis and Prevention, 27, 73-87. 
Mayhew, D. R., Simpson, H. M., \& Ferguson, S. A., (2006). Collisions involving senior drivers: high-risk conditions and locations. Traffic Injury Prevention, 7, 117-124.

Mullen, N. W., Weaver, B., Riendeau, J. A., Morrison, L. E., \& Bédard, M. (2010). Driving performance and susceptibility to simulator sickness: are they related? American Journal of Occupational Therapy, 64, 288-295.

National Highway Traffic Safety Administration (2001). Traffic Safety Facts 2000: Older Population. DOT HS 809328.

Owsley, C., Sekuler, R., \& Siemsen, D. (1983). Contrast sensitivity throughout adulthood. Vision Research, 23(7), 689- 699.

Oxley, J., Fildes, B., Corben, B., \& Langford, J. (2006). Intersection design for older drivers. Transportation Research Part F, 9, 335-346.

Raghuram, A., \& Lakshminarayanan, V. (2006). Motion perception tasks as potential correlates to driving difficulty in the elderly. Journal of Modern Optics, 53, 1343-1362.

Schefrin, B. E., Tregear, S. J., Harvey Jr, L. O., \& Werner, J. S. (1999). Senescent changes in scotopic contrast sensitivity. Vision Research, 39, 3728-3736.

Sekular, R., \& Hutman, L. P. (1980). Spatial vision and aging. I: Contrast sensitivity. Journal of Gerontology, 35, 692-699.

Sekular, R., Hutman, L. P., \& Owsley, C. J. (1980). Human aging and spatial vision. Science, 209, 1255-1256.

Skottun, B. C. (2000). The magnocellular deficit theory of dyslexia: the evidence from contrast sensitivity. Vision Research, 40, 111-127.

Skottun, B. C. \& Skoyles, J. R. (2008). Temporal frequency and the magnocellular and parvocellular systems. Neuro-Ophthalmology, 32, 43-48.

Stamatiadis, N. \& Deacon, J. A. (1995). Trends in highway safety: Effects of an aging population on accident propensity. Accident Analysis and Prevention, 27, 443-459.

Staplin, L., Lococo, K. H, Gish, K. W., \& L. Decina, L. (2003). Model Driver Screening and Evaluation Program Final Technical Report. Volume 1: Project Summary and Model Program Recommendations. U.S. DOT/NHTSA Publication No. DOT HS 809 582, U.S. Department of Transportation, Washington, DC.

Steinman, B. A., Steinman, S. B., \& Lehmkuhle, S. (1997). Transient visual attention is dominated by the magnocellular stream. Vision Research, 37, 17-23.

Summala, H., \& Mikkola, T. (1994). Fatal accidents among car and truck drivers: Effects of fatigue, age, and alcohol consumption. Human Factors, 36, 315-326.

U.S. Census Bureau, Population Division (2008). Table 12. Projections of the Population by Age and Sex for the United States: 2010 to 2050 (NP2008-T12). Release Date: August 14, 2008. Retrieved from www.census.gov/population/www/projections/summarytables.html

Wood, J. M., Anstey, K. J., Kerr, G. K., Lacherez, P. F., \& Lord, S. (2008). A multidomain approach for predicting older driver safety under in-traffic conditions. Journal of the American Geriatrics Society, 56, 986-993. 